\title{
IMAGINANDO A LOS MAYAS DE HOY: AUTORREPRESENTACIÓN Y POLÍTICA
}

\author{
Ana Rosa Duarte Duarte \\ Centro de Investigaciones Regionales Dr. Hideyo Noguchi \\ Universidad Autónoma de Yucatán
}

\section{Introducción}

Para analizar la representación y autorrepresentación de los mayas, tomo como hilo conductor Séastal: Los hijos de la Santa Gracia, una video-ficción en donde la vida cotidiana de una familia rural en Yucatán se vuelve drama y lo maya una ficción. ${ }^{1}$ Sáastal ("amanecer") surgió como un proyecto para producir material didáctico para el Programa de Maya Yucateco del Consorcio de Estudios Latinoamericanos y Caribeños de las universidades Carolina del Norte y Duke. Originalmente se planeó la producción de cuatro capitulos con una duración de quince minutos cada uno; los diálogos en cada capitulo irian de lo más sencillo hasta lo más complicado. Fueron escritos para representar tres dias en la vida de una misma familia maya. Posteriormente, se reeditaron en una obra de cincuenta y cinco minutos y se convirtieron en lo que ahora es Sáastal: Las hijos de la Santa Gracia.

Säastal retoma la teoria de lo directamente vivido y el lenguaje audiovisual del Nuevo Cine Latinoamericano, en donde también se emplean las tecnologias al alcance para privilegiar la comunicación de la realidad latinoamericana. Siguiendo esta lógica, no se usa la voz en off. ${ }^{2}$ tan tipica de los documentales institucionales o de los audiovisuales didácticos, ya que esta voz representa la autor(idad), como si fuera la voz de Dios que sale del cielo para enseñar a sus hijitos a hablar y escribir maya. En este sentido, se entiende por autor(idad), ${ }^{3}$ aquel

\footnotetext{
'Este articulo es resultado de un proceso de trabajo iniciado con la presentación de los roshes de la milpa en el V Congreso Internacional de Mayistas, realizado en Xalapa, Veracruz, en julio de 2001. También fue presentado comso ponencia intitulada "La ficción de lo maya", en el Congreso Internacional Translocalidad: diálogo sobre la cultura y el cambio en el siglo xo1, realizado por CASCA. SANA-UADY, en marzo de 2005 , en Mérida, Yucatin; asi como en la Mesa de trabajo Género y representación: medios y politica; en nowiembre de 2006 , llevada a cabo en Mérida Yucatin. La primera versión del artículo fue evaluada por el comite dictaminador de la Revista Liminar en 2005 , a cuien agradezco infinitamente sus observaciones. Aprovecho asimismo esta oportunidad para agradecer a los dictaminadores de la revista Estudios de Cuttura Mova por sus comentarios.

${ }^{2}$ Es por eso que muches documentalistas se refieren a esta forma de narración como "vox de Dios".

${ }^{3}$ Autor(sdad) es un concepto que forma parte de la discusiôn acerca de discurso mayor o litera. tura mayor y discurso mesor o literatura menor, en donde el discurso mayor a literatura mayor es el discurso de las autoridades, discurso que esti dentro de los cinones del Saber, es individual e institucional. Vẻase Duarte, 2006.
} 
individuo que ejerce su poder de hablar en nombre de toda una población. Sin embargo, esta autor(idad) es individual, institucional y está dentro de los cánones del Saber (Duarte, 2006: 129-181). En contraste, el "cine de lo directamente vivido" retoma la voz colectiva y lo banal de la vida cotidiana; es decir, la base de cualquier cultura viva y en movimiento. ${ }^{4}$ Por lo tanto, la lentitud del paso del tiempo, lo rutinario y lo repetitivo de las actividades en la vida cotidiana, son aspectos destacados en Saiastal.

La representación de la cultura maya en Sáastal, tanto durante su producción como en la obra terminada, fue un proceso de producción de conocimiento, desde mi perspectiva como nativa de la misma cultura maya. ${ }^{5}$ Los dialogos que fueron escritos en español y traducidos al jach maya o "maya puro", como lo llama Bevington, citado por Wammack (2004b: 10), ${ }^{7}$ pusieron en entredicho el idioma maya tal como se habla y vive en la vida cotidiana. El jach maya que se habla en Sáastal fue comentado por los pobladores del oriente del estado de Yucatan y otras poblaciones, como raro, y que tal vez es la manera como hablan los mayas que están por allá más lejos [Castillo y Quetzil, 2004: 1-32). Cabe destacar que no es lo mismo vivir y experimentar la vida cotidiana en una pequeña población maya en Yucatán, que representarlo yo autorrepresentarlo a través de diálogos e imágenes.

El proceso de producción de Säastal (1998-2004) es una de mis primeras experiencias en la buisqueda de otras formas de poner al alcance de las comunidades mayas los resultados de mis trabajos de investigación. Mi participación en el guión de Sáastal se basó en mi experiencia de investigación en cuatro Unidades Agricolas e Industriales para la Mujer s (UAIM) (véase Duarte, Wammack y Mena:

\footnotetext{
${ }^{+}$Véase Wammack (2004b: 3). Gabe agregar que no podría existir el cambio cultural sin la bana. lidad de la vida cotidiana.

${ }^{5}$ Naci en una población de Yucatin, dande inicié mi educación escolar y de dande ensigré a la ciu. dad de Mérida para concluir la licenciatura en Ciencias Antropologicas. Durante mi formación como antropóloga, nunca pude lograr la distancia cque requiere el trabajo profesional de un antropólogo. Pero apresdi a valorar la diferencia entre los conocimientos y la riqueza de la relación intersubjetiva, en donde tanto el sujeto antropólogo como el sujeto de una cultura aprendemes a compartir nuestros conocimientos.

'Por un especialista en el rescate y la promociòn del idioma maya en Yucataín, asi conso en la ensetianza del jadi mera.

'En sa ensima sobre el proceso de producción y dirección de Saastal, Wammadk (2004b) retama a Bevington, quien se refiere al joch maye como "maya puro" porque evita la contaninación con palabras en espariol. El ject maya es dificil de entender parn aquellos que viven cotidianamente la cultura.

" Uno de las programas de gabierno que en la década de los ochenta tuno como objetivo apo. yar la economia campesina, a través de las organizaciones de las mujeres, para acceder a créditos $y$ convertir en pequenas industrias sus actividades tradicionales y artesanales. Mi interés en hacer investigación en este campo fue descubrir qué hay detrás de los discurses políticos y académicos, que consideraron la participaciỏn de las mujeres en las organizaciones como un bienestar para las propias majeres campesinas y sus familias. Con ese abjetivo analice diex casos de las 228 Unidades Agricolas e Industriales para la Mujer (UAiM), que en 1988 ya existian en el estado, y de ellos elegi dos para realizar un estudio más profundo. De 1995-1999, participé en el examen de cuatro UAIM que se dedicaban al bordado, al urdido de hamacas, cria de pollos y ganado vacuno, asi como all cultimo del hesequén. Para mayor información, véase Duarte, 2000.
} 
1999), así como en el documental procesual "Arroz con leche", que iniciamos en 1997 (Duarte y Wammack, 1997-2008). ${ }^{9}$

Para analizar el proceso de realización de Sáastal y hablar de la representación y autorrepresentación de los mayas, me baso en las reflexiones de Tuhiwai, ${ }^{10}$ quien senala que ser investigador/a de la propia cultura nativa indigena no es suficiente para garantizar que el trabajo tenga un enfoque indigena. $Y$ ser investigador/a de una institución, por lo general, implica que el trabajo siempre estará encaminado a satisfacer los objetivos de la institución financiadora (Tuhiwai: 2002). Estas consideraciones son muy importantes para reflexionar acerca de nuestra responsabilidad con la sociedad y como productores de conocimientos, sobre todo para aquellos que, como yo, somos antropólogos nativos de la misma cultura que estudiamos. ${ }^{11}$

Mi participación en el proceso de producción de Sáastal llevó a hacerme las siguientes preguntas: Lqué relación tienen nuestros objetivos de investigación con las politicas de financiamiento, ya sean de alguna institución nacional o internacional, o de un sistema de becas?, ¿qué papel tenemos en la construcción de la alteridad que representamos, en los materiales audiovisuales que producimos o en los documentos que escribimos y publicamos?, Zcómo representamos la diversidad de la cultura maya los antropólogos nativos de la misma cultura?, ¿cómo participamos en las políticas de valorización del conocimiento? y ¿cuál es el destino de los resultados de nuestros trabajos de investigación? Éstas son algunas de las preguntas que guiarán el análisis de los temas que se abordan en Siastal.

\section{Sáastal: Las hijos de la Santa Gracia}

Para la representación de la vida cotidiana de una familia maya en Sáastal se construyó un espacio ficticio de diversos escenarios: en el municipio de Oxkutzcab, se filmó la escuela primaria de la comisaria de Cooperativa; en el municipio de Tekax, la iglesia y la zona arqueológica de Labná, que forma parte de la ruta turistica más conocida como "la ruta Puuc":12 en el municipio de Santa Elena, la casa tradicional, el palacio municipal, el parque y la iglesia; en el municipio de Muna, el mercado municipal, la terminal de autobuses y los puestos de arte-

\footnotetext{
"En "Arroz con leche" se documenta la vida cotidiana de cuatro mujeres que durante mi investigacion de campo de 1988-1998 fueron presidentas de sus organizaciones. Lo mis importante en este trabajo de documentación que iniciamos en 1997, son los procesos de cambio a lo largo de diez. ahos en la vida cotidiana de estas cuatro mujeres mayas y de sus familias.

a Indigena maori de Nueva Zelanda, que actualmente es directora del Instituto de Imestigación Internacional para los Mabri y de Educación Indigena, en la Universidad de Auckland. Véase Tuhinwai, 2002.

"Este es un tema que trato mis ampliamente en Duarte, 2007.

${ }^{12} \mathrm{~L}$ r ruta Puuc esta conformada por varios sitios arqueológicos, entre los más promovidos está Uxmal.
} 
sanias; en el municipio de Valladolid, la milpa y las tres Cruces en la comisaria de Xocen, asi como el cenote Sambulà en la comisaria de Dzitnup; y en el municipio de Abala se filmó el taller de bordado.

El primer dia en la vida cotidiana de la familia maya en Sáastal gira alrededor del regreso de Alicia a su pueblo natal, después de 15 años de ausencia. Cuando Alicia tenia 12 años, su familia emigró a Halachó, ya que su padre es originario de esa población. Ahora, la joven Alicia de 27 años regresa para solicitar su ingreso al taller de bordado al que pertenecen sus amigas de la infancia, Margarita y Teodora. La vida cotidiana de Margarita y su esposo Marcelino, está representada como la de cualquier familia contemporánea en el medio rural. Forman parte de la familia, sus tres hijos pequeños. Manuel, Maria y Felipa, la abuela (madre de Margarita) y Chucho (sobrino de Marcelino).

En Säastal, las presentaciones de los personajes inicia con el viaje de Micia a su pueblo, su llegada y su recorrido por las calles hasta llegar a la casa de Margarita. El encuentro de las amigas está mezclado de recuerdos que platican sentadas en las hamacas. Marcelino y Chucho llegan a casa después de un día de trabajo en la milpa, se hacen las respectivas presentaciones y le dan la bienvenida a Alicia. Margarita le pide a Chucho que vaya por sus hijos a la escuela e inmediatamente después, invita a Alicia a pasar a la cocina para visitar a su madre, la abuela. Cuando los niños regresan de la escuela, Margarita los presenta a Alicia. Se destaca la preparación de las tortillas como una actividad importante en la que participan la abuela y Margarita. Después de la comida del medio día, Margarita lava los trastes y le pide a su hijo Manuel que vaya en busca de su tia Teodora, porque está de visita su tia Alicia, que llegó de Halachó.

Margarita es miembro del taller de bordado chur k'aab (bordado a mano), pero debido al nacimiento de su tercera bebè, no está asistiendo con frecuencia al taller, aunque sigue bordando en su casa. Teodora presenta a Alicia con doña Gloria, la representante del taller. Alicia es aceptada inmediatamente en el grupo, basado en su experiencia en el trabajo del bordado a mano. Al anochecer, toda la familia se reune alrededor del televisor para ver el noticiero en maya y/o las telenovelas. De esta manera concluye el primer dia en la vida de la familia maya en Saiastal.

El amanecer del segundo dia, después de la llegada de Alicia al pueblo, es el inicio de un nuevo dia en la vida de esta familia maya, en donde la preparación del desayuno para los milperos está a cargo de Margarita y la abuela, mientras que Alicia y los niños duermen. Los milperos, Marcelino y Chucho, salen de su casa desde el amanecer y llevan consigo pozole para apaciguar el hambre y la sed, mientras regresan a casa. La producción del maiz para el autoconsumo es de temporal según el sistema de tumba, roza y quema del monte, conocida como la milpa. ${ }^{13}$ Chucho es un joven que llegó de la ciudad para aprender de su tio Marcelino, las labores de la milpa. Marcelino, al igual que otros campesinos de

\footnotetext{
D Para los interesados en el tema, véase Lazos (1995 y 1999).
} 
20-40 años de edad, también emigra a Cancún, donde trabaja como jornalero en albañileria durante los recesos ${ }^{14}$ de las actividades en la milpa. Son muy pocos los casos en que los mayores de 50 años siguen emigrando para trabajar, pues la emigración es una estrategia más en la economía de autoconsumo, a menos que haya un empleo fijo.

Una vez que los milperos se van a trabajar, Margarita, la abuela y Alicia desayunan, al mismo tiempo que planean el guisado para el almuerzo del medio dia. Alicia y la abuela van de compras al mercado, para traer a casa la carne y las verduras necesarias para el guisado. Las actividades en el hogar y en la milpa tienen un tratamiento paralelo en Sáastal, pues mientras las mujeres y otros miembros de la familia realizan las labores domésticas, los milperos cosechan la producción de la milpa, al mismo tiempo que Marcelino le explica a Chucho el proceso de la siembra de los diferentes productos. Marcelino y Chucho hablan de todo lo relacionado con los cuidados que se requieren para una buena producción de maiz, espelón, frijol, ibes, chile y calabaza, entre otros productos. También hablan de la importancia de la lluvia para lograr una buena cosecha, así como de los riesgos que implican los desastres naturales, que en ocasiones acaban con todo un año de trabajo.

A su regreso a casa los milperos llevan a cuestas los sacos de la cosecha. Mientras tanto Margarita y la abuela preparan las tortillas, al tiempo que Alicia cuida a Felipa, la bebé de la familia. Cuando Marcelino se sienta a descansar en la cocina, Alicia le entrega a la bebé y prepara el agua de fruta para acompañar el almuerzo de la familia.

Después del almuerzo, Chucho baña a los cerdos que están en el solar y luego sale de la casa para trabajar como tricitaxista. Al mismo tiempo Teodora y Alicia llevan a la tienda de artesanias el hipil bordado en punto de cruz que Margarita les encargó. A Margarita le urge que se venda el hipil, pues quiere comprarle zapatos a su hijo Manuel, para su próximo viaje a la zona arqueológica de Labná, en la ruta Puuc. Este viaje forma parte del plan de estudios de la escuela primaria donde Manuel va a estudiar todos los días. Maria estudia en el Kinder que está al lado de la primaria.

Alicia y Teodora hacen un recorrido por la población y hablan del anuncio del baile de jarana que se llevará a cabo en el palacio municipal. También platican acerca de los cambios ocurridos en el parque, de la restauración de la iglesia, donde se casó Teodora, y de la señora de la tiendita que acostumbraba regalar dulces a los niños. Cuando Chucho las encuentra, las invita a subir a su tricitaxi para llevarlas de regreso a la casa de Margarita, y en el trayecto, tanto Teodora como Chucho le enseñan a Alicia la oficina de Correos, la escuela de Manuel y Maria, asi como la oficina del Registro Civil. Con la llegada de Teodora y Alicia

${ }^{14}$ En tiempos pasados, los recesos en las actividades de la milpa eran utilizados para la siembra de los productos que complementaban la alimentación, asi como para el acovidicionamiento de los espacios de la vivienda y la preparación del terreno para el nuevo ciclo de la milpa. 
a la casa de Margarita termina el segundo dia en la vida de la familia maya en Saiastal.

El tercer dia inicia con el amanecer y los preparativos del viaje de Manuel y sus compañeros de escuela al sitio arqueológico de Labná. Margarita y Nicia procuran que Manuel esté bien arreglado para ir a la escuela. Alicia lo lleva y al llegar, el maestro reúne a todos los niños en el salón de clases y los prepara para vivir la experiencia. Posteriormente suben al vehiculo que los transporta a Labna. Al llegar al sitio arqueológico el maestro explica la historia de los antepasados, sus costumbres y tradiciones relacionados con los edificios arqueológicos y centros ceremoniales, además de responder a las preguntas de los estudiantes. Con este recorrido de los niños a través de la historia de sus antepasados, el maestro da por concluida la sesión de trabajo y llega a su fin Sáastal.

En Sãastal se aborda el tema del autoconsumo, entendido como las estrategias de conformación del ingreso no monetario en los sistemas de producción campesino, altamente integrados al mercado y a la producción monetaria. ${ }^{15}$ Por ejemplo, el territorio yucateco está dividido en microrregiones, de acuerdo con el tipo de producción que predomina: maicera, henequenera, ganadera, pesquera y fruticola. En la zona maicera es común que los ingresos que se obtienen a través de la emigración, estén encaminados a complementar los gastos familiares durante los trabajos en la producción del maiz, la apicultura, asi como la cria de animales en el solar. ${ }^{16}$ La milpa sigue siendo una actividad importante, ${ }^{17}$ aun en las comunidades marginales a la zona agroindustrial que es caracterizada por la agricultura de riego dedicada a la fruticultura y la horticultura, que se comercializa en el mercado de Oxcutzcab. ${ }^{18}$

La producción de los alimentos en el hogar, las labores domésticas, así como la elaboración de los hipiles bordados y las hamacas para uso propio o para vender, también forman parte del sistema de auto-consumo. En el sistema de autoconsumo, los intercambios y las donaciones son una parte importante de la forma de vida de los milperos, pues durante las ceremonias familiares y comunitarias hacen donaciones, pero tambièn reciben donaciones como Procampo y Oportunidades. ${ }^{19}$

La educación escolar de los hijos es otro tema importante en Sáastal, sobre todo en la última década en que Oportunidades está apoyando la alimentación de los niños y su participación en la educación media-básica. Sin embargo, en la actualidad, la educación escolar en el medio rural es considerada por los padres

\footnotetext{
15 Véase Torres. 2002

is Sobre el tema de los solares, véase Medina, Rejōo, Repetto y Rosales $\{2003\}$

12 Véase Rosales y Rubio, 2004.

it Véase Lazos, 1995.

1 Tanto Procampo como Oportunidades son programas del gobiemo federal, el primero está dirigido a apoyar la producción de maíz en la milpa, mientras que el segundo es para "combatir" la pobreza en el pais. Aunque esto sólo lo sabes los gobernantes y las instituciones intemacionales como la ONU, cayas evaluaciones se basan en estadisticas y gräficas.
} 
de familia como un medio más para que sus hijos puedan relacionarse con los que hablan español y no tanto como un mecanismo de movilidad social. Por ejemplo, muchos padres consideran que las personas que saben leer y escribir, así como hablar español tienen más oportunidades para establecer relaciones con otros sujetos en otros espacios. Por consiguiente, actualmente privilegian la asistencia de sus hijos a la escuela, como parte de su formación para su vida futura. Pero, si alguno no desea hacerlo, tampoco los obligan, porque reconocen las diferencias entre personalidades y habilidades.

En Sáastal se revalorizan los simbolos culturales en lugar de disminuirlos. Es decir, las imágenes están encaminadas a destacar la importancia del milpero y su familia, además de los productos tradicionales de la milpa. Por consiguiente, se emplean muchos planos "contra-picadas", donde se magnifica al personaje del milpero, asi como primeros planos de partes del cuerpo, como los pies con alpargatas o las manos cosechando los productos de la milpa. También podemos ver muchas imágenes de los rostros.

La radio y la televisión tienen un tratamiento ligero en la vida cotidiana de la familia maya representada en Sáostal. Por ejemplo, la música del radio se escucha al fondo de las escenas del desayuno de los milperos que se preparan para ir a trabajar en la milpa. El programa de radio a las cinco de la mañana es hablado en maya y con música variada en español. Por lo general, las familias del área rural prenden el radio para oir la música como fondo y para saber la hora. La televisión es para ver las telenovelas en los recesos de las labores del dia, por ejemplo al medio dia, aunque lo más común es que toda la familia se reúna alrededor del televisor por las tardes y al anochecer para ver las telenovelas, los programas cómicos o los noticieros.

En el proceso de producción de Sajostal participamos un total de cuatro antropólogos: el director y productor, ${ }^{20}$ el coordinador académico, el traductor de los diálogos al maya y yo. La producción, dirección y el guión se hicieron con una metodologia transdisciplinaria y con base en el cine de lo cotidiano. Los dialogos en español fueron escritos conjuntamente por el director y el coordinador académico, maestro de maya en el Programa de Maya Yucateco. La traducción al maya de los diảlogos estuvo a cargo de un especialista en la enseñanza del idioma, hablante nativo del maya. De la supervisión de los diälogos durante la puesta en escena nos ocupamos el coordinador académico y yo. La edición y postproducción fue responsabilidad del director, pero la edición de los diálogos en maya estuvo a mi cargo.

\footnotetext{
II A quien me referiré de aqui en adelante únicamente como director. Creo corweniente bablar de la diferencia entre un director de una pelicula y un productor, ya que no es la mismo. El director es el responsable de la relacionado con el uso creatio de las imágenes, del guión cinematogrifico y del proceso de filmación; mientras que el productor es ell responsable directo de la realización de la pelicula y por tanto, es el encargado de toda la logistica de la producción, que implica tanto la administración de los recursas financieros como la planeación y coordinación de los lugares y las locaciones, de los dias de filmación, del personal necesario para cada dia de filmación, del equipo de sonido y filmación, del vestuario, la alimentación, el alojamiento, el transporte, etcétera.
} 
El equipo de producción también contó con la participación crucial de otras personas. La productora ejecutiva fue clave en el proceso de producción de Sáastol, ya que su búsqueda por hacer algo fuera del canon es lo que hizo que el proyecto fuera posible. Asimismo, se contó con la valiosa participación de un cineasta cubano como director de fotografia, quien contribuyó con su larga trayectoria de trabajo en el Nuevo Cine Latinoamericano. Tambièn colaboró en la elaboración del guión cinematográfico.

De los cuatro antropólogos que participamos en Sáastal, tres nacimos en poblaciones mayas y tenemos el idioma maya como lengua materna. Sin embargo, nuestras experiencias de vida estan marcadas por las circunstancias especificas en las que crecimos, asi como las redes de relaciones con otros sujetos. Por ejemplo, ninguno de nosotros se formo como milpero, a pesar de que algunos de nosotros crecieron en una familia milpera. No es lo mismo ser hijo/a de un milpero $^{21}$ que ser milpero, ya que cada sujeto ${ }^{22}$ está constituido en las redes de relaciones de poder que se establecen con otras fuerzas y en otros espacios (Duarte, op. cit.). ${ }^{23}$

Mi experiencia en el equipo de trabajo me llevó a plantear las siguientes preguntas: ¿cómo vivimos "lo maya" los nativos hablantes de maya, sobre todo aquellos que, como yo, somos antropólogos?, ${ }^{24}$ Llo vivimos como indigenas, como antropólogos o de acuerdo con la situación que se nos presente? Teniendo en consideración estas preguntas, en el siguiente apartado analizo cómo los mayas imaginamos, representamos y sobre todo auto-representamos a los mayas en Sáostal.

\section{Imaginando "lo maya" en la globalización}

Giddens (2000) subraya que en la globalización hay una mayor propensión a representar las culturas indigenas como espectáculo, lo que Schiwy (2002) llama la instrumentalización de la cultura. Esta propensión no solamente es producto de las politicas indigenistas de rescate cultural y del folclor para el turismo extran-

II Desde pequeña acompané a mi padre al rancho para apoyarlo en las labores del campo, sa. cando agua del pozo para llenar las piletas donde tomaban agua los ganados y participando en la quema del monte durante la preparación de las tierras para la siembra del maiz. También cooperé en la cosecha de los elotes, iba por la lena y, desde luego, también aprendi el quehacer del hogar, de acuerdo cos el "cómo deberia ser una buena mujer", según los discursos de mi época:

${ }^{21}$ En este trabajo, sajeto es diferente a "individuo" y al "yo", ya que me refiero al sujeto que se constituye colectiva y co-extensivamente en las relaciones de poder del cuerpo y con todo lo que le rodes. Este concepto es tomado de Wammack, quien a sa vez se basó en los trabajos de Spinoza y atros autores, véase Wammack, 1997.

${ }^{2} \mathrm{~L}$ agencia de los sujetos es un poder de hacer que se constituye y actualiza a cada momento en la vida cotidiana. Este poder es diferente del poder de autoridad, poder de control, poder representado, poder vacio o poder ounipresente.

${ }^{34}$ A pesar de que mis padres vivierne con la política de acabar con el idioma maya, creci plati. cando en maya con otras personas de la población. 
jero, sino de nuestro imaginario que nos lleva a autorrepresentar nuestra cultura de acuerdo con estos modelos identitarios, ${ }^{5}$ lo que yo llamo el performance de las identidades. ${ }^{26}$ En Sáastal, esta propensión a autorrepresentar nuestra identidad como una ficción, asi como "performar" e instrumentalizar la cultura, se debio, por una parte, a nuestra presencia en calidad de antropólogos y a la de otros extraños que participamos en la producción (Grimonprez, 1998), ${ }^{n}$ y por otra parte, al poder de hacer de los mayas como sujetos activos en la cultura...8

En Sáastal, estas identidades suaves ${ }^{29}$ de los mayas se reflejan en la autorrepresentación encaminada a satisfacer el imaginario de los ajenos a la cultura. Por ejemplo, el uso del calabazo por parte de uno de los actores, cuando en su vida real no lo haria, ya que trabaja como chofer. Además, son muy pocos los campesinos que aún usan calabazo, pues lo han sustituido por botellas de plastico recicladas. Así que, las identidades suaves son identidades maleables en donde las acciones de los sujetos en la vida cotidiana, los convierten en sujetos políticos, ya que aprovechan las posibilidades de actuar sin confrontación con tas normas sociales, to que posibilita su existencia y expresa su resistencia (Wammack, 1997). Las identidades suaves son diferentes de las identidades que se conforman respecto a un imaginario de un "nosotros" como principio de valoración.

L.a autorrepresentación de la vida cotidiana maya, de acuerdo con el imaginario ${ }^{30}$ de cada uno de los que participamos en Sáastal, refleja la convivencia de la cultura maya de autoconsumo y la cultura del consumismo, ${ }^{31}$ y por lo tanto.

${ }^{5}$ Un caso ejemplar es el perfonmance de Coco Fusco y Guillermo Cómex Peña (1992), “La pareja enjaulada", en el que estaban encerrados en una jaula, supuestamente corso una pareja de indigenas arawak "no descubiertos". De esta manera representaron el imaginario del indio americano para los visitantes a las exposiciones del quincuagésimo aniversario del "descubrimiento" de las Américas por Gristóbal Colón, donde también posaron para fotografias mientras realizaban sus ritos "tradicionales" cotidianos. Este performanse fue realizado especificamente como una crítica, sin embargo, mouchos de los performance de "autorrepresentaciön" tienen más bien propósitos de satisfacer los deseos de los no indigenas.

36 Se refiere a la puesta en escena de la identidad de los mayas para otros públicos. Por ejemplo, usar alpargatas, en lugar de las chanclas de plástico que usan los milperos contemporáneos. El calb. bazo para cargar agua y apagar sa sed, en lugar de usar botellas de plástico recidadas. El sombrero, que es mis comín entre las milperos de la tercera edad, en lugar de usar gorras como lo hacen los milperes de veinte a cincuenta anbs.

27 Para Crimonprex, las frecuentes llegadas de los antropólogos a las poblaciones lleva a las na. tivos a redefinir sus conocimientos, pues durante su trabajo de campo entre los papuanos en Nueva Guinea, éstos le comentaron que a cada antropólogo le dan un poco de información, ya que tienes que dejar información para los antropólogos que llegarin en el futura.

14 Estas formas de actuar podrian considernise como acciones de los sajetes con poder en una cultura resistente, poder que se constituye y actualiza dia con dia.

a Cuando me refiero a identidades suives estoy extendiendo el concepto de las subjetividades suaves en la discusión entre espacio y subjetwidad en Wammadk.

${ }^{31}$ Es la manera en que idealizanos, dramatizamos y autorrepresentamos la vida cotidiana de los mayas, a traves de las imágenes.

${ }^{31}$ Consumismo es el sistema económico que está basado es las relaciones de producción de mercancias en donde las ganancias soos lo más importante. 
las rupturas, continuidades y recomposiciones de las relaciones entre los sujetos y las instituciones (Wammack, ibid.). Por ejemplo, la representación de la mujer maya en Sáastal es problemática, y no se debe solamente a la imposibilidad de tratar un tema tan complejo como es el género en un cortometraje. En primer lugar, la participación de las mujeres en las labores de la milpa, nunca fueron contempladas como una parte importante. Esto se debió al hecho de que el capitulo dedicado a la milpa fue planeado desde un principio para estar dedicado al trabajo masculino, mientras que el trabajo femenino fue pensado como todo lo relacionado con la visita al mercado y al taller de bordado. De esta manera la reducción de la vida cotidiana de una familia milpera con fines didácticos, resultó en una bipolaridad en la representación de género.

Además, después de ver la película, nos queda la impresión de que todas las mujeres son parte de organizaciones para trabajar fuera de su casa o que es común que vayan al mercado a comprar lo que necesitan para preparar los alimentos. Sin embargo, no en todas las poblaciones existe un edificio llamado "mercado" para el expendio de carnes y verduras para la preparación de los alimentos de cada dia. Es más común el consumo de la producción familiar, ya sean de la milpa o del solar.

Ante esta complejidad de la cultura maya en la globalización, nuestro imaginario como equipo de trabajo en Sáastal, fue rebasado por las situaciones que afectaron la autorrepresentación de nuestra cultura, asi como su performance e instrumentalización. Mi experiencia en la producción de Sáastal como material dídáctico me llevó a cuestionar la conceptualización de los mayas como "los antiguos" que hablaban maya y vestian de manta, alpargatas (huaraches) y sombrero si eran varones, o de hipiles,,$^{32}$ rebozos y chongos si eran mujeres. También me llevó a cuestionar por qué los describimos como aquellos que habitaban en chozas de bajareque, techo de palma, paja o piso de tierra, pues si asi fuera, las casas del Fondo Nacional para Desastres Naturales ${ }^{33}$ (Fonden, 2006-2007) ya hubieran acabado con los mayas. Si suponemos que la cultura maya está compuesta unicamente por los aspectos tangibles, visibles, y cuantificables, la cultura maya sería cosa del pasado.

La convivencia de la cultura maya de autoconsumo y la cultura del consumismo ha hecho que cada vez sea más común que los refrescos embotellados y las golosinas industrializadas formen parte de la vida cotidiana, que se hable tanto

\footnotetext{
${ }^{12}$ Actualmente, los hipiles son usados por las mestizas mayas. Induso las mujeres "en la politica" $y$ las del magisterio usan hipiles con bondades muy grandes y mary coloridos, pero a diferencia de las mestizas (mujeres mayas), generalmente tienen el cabello corto o terido. El hipil también es usado por las mujeres urbanas, solo que sus bordados son de colores andy bajos fcolor pastel).

${ }^{D}$ Durante 2006 y 2007 se invirtieron muchos recursos federales y estatales para la construcción de casas de bloques, cemento, poho y cal, hasta en los rincoses más apartados del estado. La movi. lización de les materiales fue a través de grandes traileres de "Construrama", pero muchos allbahiles recibieron "casi nada" de pago por la construcción de las casas, y por eso, los albatiles baenos en su trabajo, no participaron. Cuentan que las casas fueron mal construidas y con materiales de may baja calidad.
} 
español como maya, que se usen hipiles y otros vestidos, o que habiten en espacios construidos de cemento o de bajareque y palma. Este fenómeno se debe en parte a la migración que es cada vez más común en la globalización, tal como los movimientos pendulares entre el campo y las ciudades cercanas de los que trabajan como meseros y albañiles, jornaleros o empleados de las plazas comerciales. Esto tambièn ha hecho que sea cada vez más común escuchar pláticas en maya en diferentes espacios urbanos entre los trabajadores del llamado "sector de servicios". Esta es una muestra más de cómo la cultura maya es resistente, pues a pesar de estar afectada por la cultura del consumismo y apropiarse de elementos de ésta, no ha perdido su especificidad como cultura.

Esta capacidad de adoptar y resignificar, se expresa también en la adopción de algunos vocablos y conceptos del español al maya, sin ser una amenaza de pérdida del idioma maya y mucho menos de la cultura. La lengua materna en la cultura maya es uno de los principales medios de resistencia, ya que es primordialmente colectiva y sólo a través de ella se puede comunicar la cultura, lo que nunca se lograra a través de un idioma administrativo como el español. Tan es así que el maya en 2005 era el segundo idioma indigena más hablado en el pais. después del náhuatl, según información de la Dirección General de Educación Indigena (DGEI).

Por consiguiente, ser maya no es una cuestión de quitarse y ponerse la camiseta y tampoco es una cuestión de decir: "soy maya, porque tengo antepasados mayas". ${ }^{34}$ La cultura maya, al igual que otras culturas del mundo, no es un conjunto de atributos, sino una cultura viva y vivida a diario por sujetos que se constituyen cotidianamente y desde adentro de su cultura. Toda cultura vivida por sujetos tiene la capacidad de adoptar y resignificar elementos de otras culturas para enriquecer la suya. La adopción de elementos de otras culturas, con las que interactuan cotidianamente los mayas, se debe a su capacidad de vivir y experimentar la cultura en diferentes espacios, lo que también está relacionado con su resistencia como cultura.

Ser maya tiene connotaciones más profundas y complicadas, que van más alla de ser nativo del lugar, tener apellidos mayas o identificarse como maya. Para los mayas y para todos los indigenas del pais, el respeto a la palabra ${ }^{35}$ es uno de los principales valores en sus relaciones de poder como cuerpo colectivo (Duarte, op. cit.). Asimismo, la resistencia de la cultura se basa tanto en los

\footnotetext{
${ }^{34}$ Este es un discurso muy común del ex gobemante yucateco (2001.2007), cuya política permitió la afectación de los terrenos de los campesinos de Oxcuin. Ohichẻn Itzà y Cuzamai, en beneficio de los empresarios. Durante su gestión también realizó la expropiación del cenote "Xkelken" en nombre de la Ley, para otorgarlo a la Secretaria de Turismo, lo que antes fue una de las principales fuentes de ingresos de las habitantes de Dritnup, Valladolid.

${ }^{25}$ Muy diferente de la cultura de los politicos modernos a quienes no les importa prometer y muxbo menos cumplir, ya que el respeto a la "palabra" emperiada con toda una población de millones de mexicanos es lo de menos para el poder autoritario y dictatorial. Mientras que es las comunidades mayas, la "palabra" empeñada implica digridad, orgullo, hooor y prestigio, asi como su cumplimiento ante los miembros de sa comunidad.
} 
valores ancestrales como en los actuales: la dignidad, la bondad, el orgullo, el respeto a los demás, el respeto al medio ambiente, a la naturaleza, a sus dioses, a sus costumbres, a sus saberes y conocimientos, así como en su lucha para defender su cultura. Desde luego que estos valores no forman parte de las politicas de desarrollo, modernización y globalización, en donde lo único que importa es producir valor, sin importar la afectación y destrucción de la naturaleza. ${ }^{36}$

L.a resistencia de los mayas se expresa de muchas maneras. Muchas veces se entiende como el rechazo al contacto con otras culturas, tal como ocurrió durante la Colonia cuando los independientes y rebeldes del oriente de Yucatán huyeron a las montañas ${ }^{37}$ y prohibieron el acceso de maestros a sus comunidades (Sullivan, 1989). Pero también existen otras formas de resistencia, como el trabajo a media máquina (Peniche, 1999). Podriamos decir que la resistencia de la cultura maya está en esas pequeñas y extraordinarias acciones (Scott, 1985), pero sin confrontar necesariamente a la autoridad. Más bien, la resistencia está en sus prácticas cotidianas, en donde las acciones son silenciosas, se repiten y se repiten, son lentas y aburridas (en la milpa y el hogar), tal como se representa en Sóastal. Estas caracteristicas de las acciones de los mayas en la vida cotidiana han puesto en entredicho las premisas del desarrollo, la modernización y las politicas neoliberales en las que tambièn subyacen las metodologias de trabajo en las ciencias sociales.

Considero que la resistencia de la cultura maya supera los esfuerzos de negar la cultura por parte de las instituciones y de la sociedad yucateca en general, lo que ha llevado incluso a los propios mayas a decir: "tal vez los joch mayas están por allá lejos" cada vez más lejos. La resistencia de la cultura maya ha superado, en muchos aspectos, las politicas nacionalistas inspiradas en la Constitución mexicana de 1917, tal como las politicas indigenistas que retomaron mucho de la ideologia modernista del Porfiriato, durante el cual el sistema educativo y la Iglesia se encargaron de modernizar a los indigenas ${ }^{38}$ para la construcción del Estado-Nación (Savarino, 2006).

Mi experiencia en la producción de Sciastal me ha hecho reflexionar en términos más amplios acerca de la negación de mi cultura en la que también participan otros especialistas y autoridades en los estudios mayas, al dar por sentado que la igualdad y el desarrollo, sólo se lograria a través de las politicas educativas encaminadas a la eliminación de la diferencia cultural. Cabe destacar que muy pocos cuestionan en profundidad este aspecto de las politicas educativas. Gustavo Esteva es uno de los pocos intelectuales que desde la década de los noventa se ha preocupado por los efectos negativos de las politicas educativas para la pluralidad cultural en México. Y se ha preguntado por qué educar para

\footnotetext{
${ }^{36}$ Hay que destacar que los discursos en torno al desarrollo sustentable han ido en aursento, sobre todo en cuanto al discurso, pues no hay evidencia de sus acciones en la vida cotidiana.

17 Para los mayas y otros indigenas del pais, las montanias sou el monte alto, que en el caso de Yucatin se encuentran en la frontera con Quintana Roo.

3 Vèase Savarino, 2006.
} 
expulsar mano de obra, en lugar de educar para mejorar la producción del maiz, principal alimento en la economia de autoconsumo. 3

Ésta es una buena pregunta para reflexionar acerca de las contradicciones entre la representación y la autorrepresentación en Säastal. Por ejemplo, ninguno del equipo de trabajo sabia todas las implicaciones de la persistencia del sistema de autoconsumo en la sociedad consumista y que gran parte de los productos para la alimentación todavia se producen en la milpa y en el solar. $Y$ por eso, las mujeres salen al mercado para comprar la carne y verduras para el guisado del dia, a pesar de que no es común que las familias vayan todos los dias a comprar sus alimentos al mercado. Desde luego, las situaciones encontradas en el mercado - la repetición de numeros, nombres de verduras y colores, etcétera-. apoyan el aprendizaje del maya.

En 2005, Drucker también destacó su preocupación acerca de las politicas de abandono del campo y de la producción del maiz, al señalar que "un pais que no produce sus propios alimentos está condenado a acabarse". Parafraseando esta preocupación, le agregaria que "un pais que privilegia politicas que niegan la pluralidad cultural para privilegiar a unos cuantos, está condenado al servilismo de los paises más poderosos". Basta con señalar la vulnerabilidad actual de nuestra economia frente a las crisis económicas de nuestro vecino pais del norte, lo que se debe en parte a la negación de la diferencia cultural y a la negación de las economias de autoconsumo y de las culturas indigenas.

Algunos de nuestros estudios en el medio rural parten del supuesto de que el bienestar está en el desarrollo y la modernización, en donde ef abandono de la milpa y el aumento de la emigración son parte del proceso. El doble discurso en la sociedad globalizada justifica el despojo de las tierras, la marginación y pauperización de la mayoria de los pobladores, mientras que crecen los medios de control politico y social. En este mismo sentido, la modificación del articulo 27 de la Constitución mexicana, "en nombre del bienestar de los campesinos", también es parte de la modernización. Incluso el despojo a los campesinos de sus tierras y la acumulación de terrenos en manos de algunos, también son parte de la modernización. Frente a este doble discurso, las politicas de desarrollo y modernización pueden parecer engañosas y hacernos creer que la emigración de los sujetos responde únicamente a la satisfacción de necesidades. Por lo tanto, hay que preguntarse: Lla emigración para trabajar como albañiles o como empleados en las maquiladoras es una respuesta a las necesidades económicas, o existen otros motivos?

Cuando en nuestros estudios partimos del supuesto de que el desarrollo y la modernización implican bienestar, utilizamos indicadores como el ingreso, las actividades de cada uno de los miembros de la familia, el número de familias en el hogar, modelo de la vivienda, tipo de vestido, el uso del idioma español y el maya, los enseres domésticos y la cantidad de cosecha de la milpa yio la parcela. En este modelo de analisis no hay cabida a la heterogeneidad de las relaciones,

"Castavo Esteva, comunicatión personal, Oaxaca de juairez Oaxaca, agosto de 2002. 
en donde se requiere tomar en cuenta otros indicadores menos tangibles, como el uso de los espacios en sus viviendas, sus creencias, sus temores, sus prácticas, sus relaciones de poder, así como las redes de relaciones sociales, familiares y vecinales, entre otros indicadores (Duarte, 2000).

Cuando nos enfocamos al estudio de los mayas durante la conquista y su participación en la Guerra de Castas, así como en otras movilizaciones, sin llevar esta situación a los mayas de hoy, llevamos a nuestros lectores a suponer, que los mayas fueron precisamente esos antiguos, pero que ya no existen. Una tendencia más en nuestros estudios acerca de los mayas ha sido suponer que los mayas están únicamente en los espacios rurales, tienen una forma particular de gobierno, prácticas, ceremonias y rituales propios. Esto me ha llevado a preguntarme ¿qué pasa con los jövenes que cotidianamente deambulan por las calles de la ciudad de Mérida, Valladolid, Cancún, que visten y calzan como cualquier citadino, pero que hablan maya y no tienen aspiraciones de establecerse en las ciudades donde trabajan? Y ¿qué pasa con los profesionales mayas que trabajamos en universidades u otras instituciones?

Incluso nuestra insistencia en identificar a los mayas ha provocado que los mayas vivan como diáspora en sus propios lugares de origen. Por ejemplo, en la campaña mediática del actual gobierno humanista, sus anuncios están dirigidos a representarlos como espectáculo (Giddens, op. cit.: 57) para vender su cultura a los turistas, olvidando su conexión con la vida cotidiana. En estas prácticas politicas se suele olvidar que la cultura maya tiene sus bases enraizadas en la tierra, a diferencia de las bases ficticias de las politicas desarrollistas y modernistas del neoliberalismo. $Y$ precisamente sobre esas bases ficticias del neoliberalismo ha surgido la necesidad de la valorización de la cultura maya como una de las maravillas del mundo para su comercialización — política de valorización de la cual no se han salvado las instituciones de enseñanza superior, en la que tambièn participamos.

Por todo lo anterior, es cada vez más urgente que nuestro imaginario pueda trascender el sentido común, y en lugar de suponer que los programas de desarrollo sólo implican bienestar, hay que preguntarnos: idesarrollo y modernización de quién y para quién?, ¿bienestar de quién y para quién? Estas condiciones complejas de vida se reflejan en el proceso de autorrepresentación de nuestra cultura en Sáastal, como veremos en el siguiente apartado.

\section{Política y autorrepresentación maya}

La autorrepresentación que los nativos de la cultura maya hicimos de nuestra cultura en Sáastal, es resultado del largo periodo de convivencia de la cultura maya de autoconsumo y la cultura del consumismo, asi como las politicas de colonización, civilización, des-indianización y homogeneización que forman parte de un proyecto de nación. Desde luego que también ha influido el doble discurso de las instituciones, tanto gubernamentales como de la sociedad en general, al 
considerar a los mayas como aquellos a los que hay que reinventar y subsidiar. Al mismo tiempo que han fomentado el deseo de los extraños por descubrir a esos mayas exóticos, han negado la cultura maya contemporánea y marginado a los mayas. Esto lo apreció un joven videasta colombiano de visita en Yucatán en 2006, quien habia soñado conocer Chichén Itzá, pero al llegar allá se decepcionó al ver la invasión del turismo extranjero, y lo ajeno en que han convertido el lugar para los nativos de la propia cultura. Y precisamente en este contexto histórico y politico nos hemos constituido como sujetos que participamos en la autorrepresentación de nuestra cultura.

La realización de Sáastal se llevó a cabo en un contexto de constante diálogo y negociación, lo que hizo que las relaciones intersubjetivas en el equipo de producción fueran determinantes. Esta dinámica no fue limitada a las mesas de trabajo que reunieron a todos los miembros del equipo, incluyendo a los actores, sino también formó parte de la estrategia de producción en la que participaron todos. Pero también habia otros factores humanos. Por ejemplo, un embarazo de alto riesgo de una de las actrices llevó a poner fin a su participación y a incorporar a otra actriz para desempeñar su papel, afectando la representación de los roles de género en Sáastal. Esta misma dinámica y la manera en la que estábamos autorrepresentando nuestra cultura, asi como la manera en que "performamos", instrumentalizamos y convertimos en ficticias nuestras identidades, me llevó a cuestionar mis propias conceptualizaciones de mi cultura.

la misma dinàmica de trabajo en equipo caracterizó la filmación de las escenas y diálogos, y fue en este contexto en que el joch maya complicó el primer día de filmación. El esfuerzo de componer palabras mayas para sustituir las palabras españolas de uso común, resultó en la elaboración de algunos diálogos sobre los que no se pudo lograr un acuerdo en el equipo. Los mismos actores nativos de una pequeña población y hablantes nativos del maya, ya habian solicitado algunos cambios en los diálogos para facilitar la preparación de sus lineas. Pero a pesar del trabajo previo, nunca lograron captar el sentido de algunos diálogos y se dedicaron a memorizar. Esto hizo más dificil la autorrepresentación, pues cuando olvidaban una palabra en su linea, ya no tenian la posibilidad de improvisar. A raiz de esta experiencia, las correcciones de los diálogos, realizados en equipo, fueron parte del proceso.

Los actores tenian que hablar maya y estar disponibles para los rodajes. Obviamente, no todas las personas tienen la posibilidad de salir del trabajo en cualquier momento. Así que fueron seleccionados los actores de un grupo de teatro regional con trayectoria en la autorrepresentación de su cultura, ya sea en español o en maya, lo que de alguna manera facilitó nuestro trabajo, ya que estaban acostumbrados a viajar con el teatro. Los actores trabajaban como bordadores en diversos trabajos: en un taller de ropa típica, en una maquiladora y en instituciones de gobiemo. Esto facilitó su participación en Saiastal, aunque hubo que tramitar los permisos correspondientes y planear muy bien su participación, para evitar gastos innecesarios. 
La casa "tradicional" que elegimos de acuerdo con el imaginario del equipo resultó ser un museo, ya que fue una casa con techo de palma, paredes de embarro y piso de cemento. Elegimos precisamente un lugar adecuado para la autorrepresentación de nuestra cultura y para "performar" nuestra identidad. No podia ser electa una casa con techo de cartón, a pesar de que son los materiales que más se usan actualmente para los techos de las casas "tradicionales" en el àrea rural, pues son los materiales más baratos y los que el gobierno otorgaba como apoyos para las familias en aquel entonces.

L.a casa elegida conserva precisamente sus rasgos "tradicionales" para recibir a los turistas que llegan en autobuses y camionetas para conocer la casa maya, el patio y la cocina, donde la señora prepara las tortillas para que los turistas tengan la posibilidad de tomar sus fotografias del recuerdo. La visita de los turistas es importante para esta familia maya que invierte una parte de sus ingresos en la conservación de su casa tradicional. La casa se conforma tanto al imaginario turistico de los mayas que durante uno de los dias de filmación llegó un grupo de turistas que pensaron haber sido testigos de una boda maya. Pero se trataba más bien de dos jóvenes actores vestidos y maquillados para la representación de una de las escenas de Sáastol, seguin el guión cinematográfico, y estaban sentados en la hamaca esperando que se retiraran los turistas para continuar con la filmación.

La autorrepresentación de acuerdo con los modelos imaginarios, también tiende a convertir la cultura material en mercancia, tal como ocurrió con la casa. Por ejemplo, la milpa donde se llevó a cabo la filmación de las actividades de los milperos no fue la milpa originalmente planeada, sino una milpa dedicada al cultivo de los alimentos para el autoconsumo de la familia. Por lo tanto, su construcción estaba de acuerdo con las condiciones ambientales, ecológicas y legales de la época. En cambio, la milpa que originalmente fue elegida por una parte del equipo fue una milpa modelo en donde algunos investigadores experimentaron las técnicas "tradicionales" de producción de maiz. La milpa modelo fue construida seguin las reglamentaciones de la época hacendaria, cuando los milperos tenian que construir una cerca alrededor de su milpa para proteger sus cultivos del ataque de los ganados, propiedad de los hacendados. Sin embargo, por cuestiones presupuestales, no se pudo llegar a un arreglo con el dueño de la milpa modelo.

La vestimenta y la utilería que aparecen en Sáastal, son producto de una negociación entre los diversos imaginarios, a veces encontrados, de los miembros del equipo y los actores. La vestimenta de la familia maya milpera, tanto el hipil como el peinado de Margarita, asi como la ropa que usarian Marcelino, Alicia y Chucho fueron armados en colaboración con las comunidades y los actores de teatro regional. Por ejemplo, las alpargatas con suela de llanta e hilo de henequén para sujetárselo en los pies, el sombrero, el sabucán ${ }^{45}$ y el calabazo fueron propiedad

"Bolsa que en otros tiempos tejieron los propios campesinos con hilo de benequén, ahora son de plástico y siempre lo llevan consigo los milperos, para cargar sus utensilios de trabajo yóo su comida. 
del grupo de teatro regional. Mientras que la camisa, el machete y los mecapales, asi como las bolsas para cargar la cosecha fueron préstamos de las familias milperas. Hay que destacar que en muchos casos el calabazo para llevar agua al monte, por lo general ha sido sustituido por botellas de plástico reciclados. Son muy pocos los milperos que auin usan alpargatas con soga de henequén, pues es cada vez más comuin el uso de chanclas de plástico. Por lo general, el uso de sombrero es para los milperos mayores, mientras que los más jóvenes usan las gorras que los politicos distribuyen durante sus campañas, asi como gorras con logotipos de equipos internacionales de beisból o futból, tal como la que usa Chucho. En otros sentidos, la ropa usada en Sáostal puede ser considerada tipica de la actualidad, ya que la ropa de algodón blanca, a la que se refieren muchos escritos acerca de los mayas de la época hacendaria, ha sido sustituida por ropa de poliéster y por lo general de colores obscuros, debido a su resistencia y mayor protección de la maleza y de los rayos solares.

Siguiendo con la idea de lo "tradicional" en Sáastal, la musicalización podria haber sido prehispánica, pero se utilizó la música que se escucha cotidianamente en las poblaciones, una combinación de cumbias locales y nacionales. También se utilizó algunos materiales de maya pax (música de los mayas), así como una versión reciente de una de las mismas melodias. Los músicos de maya pax vienen de las pequeñas comunidades de Yucatán y Quintana Roo e interpretan su música por invitación en la estación de radio "La voz de los mayas" (XEPET), en Peto, Yucatán, $y$ las grabaciones forman parte de la fonoteca.

Sáastal, no sólo puso en evidencia nuestras conceptualizaciones acerca de la cultura maya, sino que el juego entre la representación y la autorrepresentación involucró a cada uno de los que participamos como sujetos en la video-ficción, tanto durante el proceso de producción, como actualmente a través de las imágenes y los diálogos mayas. Esto puso en entredicho la autenticidad de la representación y autorrepresentación de la cultura maya, asi como la veracidad del documental y la falsedad de la ficción. Pero también puso en evidencia que todos somos sujetos politicos, y que la manera en la que representamos la otredad o autorrepresentamos nuestra cultura corresponde a los imaginarios que adoptamos y a las situaciones sociales, culturales e institucionales a las que nos sometemos. Por lo tanto, el trabajo de equipo se vio afectado por divisiones, por un lado, los que estábamos sujetos a las politicas institucionales encaminadas a fomentar la productividad acadèmica individual, y por otro lado, los que desempenaron papeles creativos. Esta división fue concebida por algunos como una división entre técnicos y profesionales.

Tal apreciación, que valora la producción del conocimiento sólo dentro de los cánones, privilegiando los textos impresos por encima de los medios más accesibles, como es la tradición oral, los acuerdos verbales, el lenguaje gestual o audiovisual, forma parte de la negación de las culturas indigenas, como la maya, que todavia dependen de otros medios de comunicación y producción de conocimientos. Sáastal, no es el resultado de una investigación - un "informe"-, sino un documento audiovisual creado colectivamente, en el que se retoma ta teoria. 
el video digital, la lengua maya, los conocimientos de milperos y artesanas, entre otros, y se comunica una historia compleja a través de un lengua audiovisual accesible a todos los que hablan maya, sin importar su edad, nivel de escolaridad, ocupación o profesión, tal como se ha podido ver las veces que se ha proyectado al aire libre en las diferentes poblaciones. En estas proyecciones, Saiostal siempre ha despertado comentarios acerca de las representaciones y autorrepresentaciones mayas, asi como del jach maya que se habla.

\section{A manera de conclusión}

Con este apretado resumen de mi experiencia al participar en la realización de la ficción Säastal: Los hijos de la Santa Gracia, analizo mi desempeño como nativa de la misma cultura maya, y mi compromiso con la institución académica de la cual también formo parte. En este artículo, me he enfocado tanto en las maneras en que fue representada nuestra cultura en Saiostol, como en las maneras en que la autorrepresentamos, los nativos de la cultura. $\mathrm{Al}$ analizar las imágenes de los tres dias en la vida cotidiana de la familia maya en Sáastal y el proceso de producción como equipo - antropólogos, actores de teatro regional, otros actores sociales, entre otros-, se hizo evidente nuestra propension a "performar" e instrumentalizar nuestra cultura y a convertir en ficticias nuestras propias identidades.

Originalmente, nuestro deseo era representar la cultura maya a través de una familia tipica. Sin embargo, nuestra participación en el proceso de producción nos llevó a representar y autorrepresentar nuestra cultura, a través de una familia "prototipica", pero a fin de cuentas muestra contradicciones y simplificaciones que reducen la diversidad de prácticas y costumbres a una familia ficticia e idealizada. Esta ficción resultante de una familia que parece ser culturalmente auténtica, a fin de cuentas no podria existir, debido a lo inusual de los diálogos en jach maya, que hasta a los abuelos les parecen extraños. Tambièn existen otras contradicciones como las de los milperos hablando de manera pesimista acerca de los multiples riesgos en sus milpas y las mujeres que van al mercado a comprar las calabazas, cuando en una economia de autoconsumo, entre los alimentos básicos de la familia estain las calabazas, que visualmente se pueden ver en Sáastal como uno de los productos de la milpa.

l.a video-ficción Sáastal ha provocado diversos comentarios, entre los que está el de un especialista que describió Sóastal "como una rara, pero hermosa viñeta etnográfica acerca de un pueblo maya contemporáneo".41 Durante la proyección de Sáastal al aire libre en las comunidades, la representación de los diálogos mayas al joch maya fue comentada: "hablan raro, pero tal vez asi hablan los joch mayas que están por allä", muy lejos.

${ }^{4}$ Allan Burns, director del Departamento de Antropologia, Universidad de la Florida es Gaines: ville, Estados Unides. 
Las siguientes imágenes son fotogramas del video que analizo en este articulo:

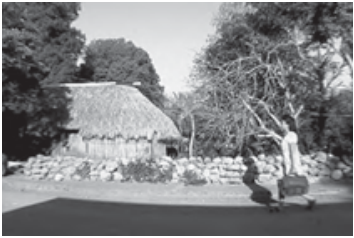

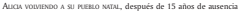

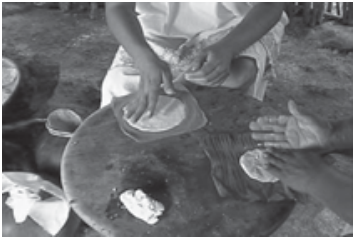

Mujekes referawbo las meress para el almuerzo de los ninos que llegan de la escuela, los campesinos que regresan de la milpa y el resto de la familia 


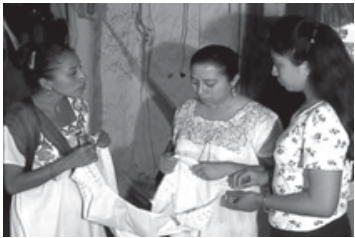

Teopora, Mancavria y Auruh ide izquierda a derechal hablando del bordado, unos momentos antes de que Teodora acompane a Alicia al Taller de bordado

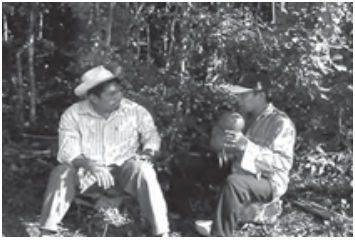

Mugcetavo y Burtoto, tio y sobrino preparando y tomando su pozol hecho con el agua de su calabazo. Al pozol es una bebida que mitiga la sed y el hambre, mientras regresan a casa 


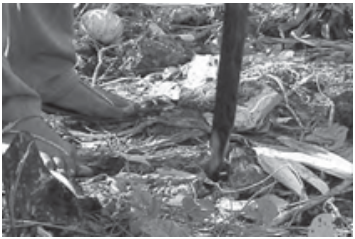

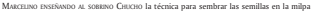

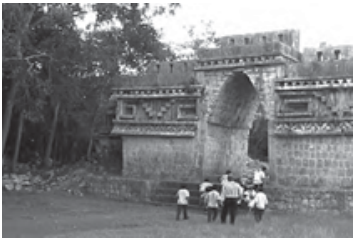

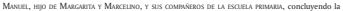
visita a la zona arqueológica de Labná, como parte de su programa de estudios 
Todo esto me lleva a conduir que una detallada lectura de Sáastal no sólo pone en entredicho la representación de la vida cotidiana de la familia maya, representada aqui como un "otro" auténtico y real, sino también pone en entredicho la autorrepresentación de la "verdad(era)" identidad maya. Asimismo, problematiza nuestras participaciones, tanto en la representación como en la autorrepresentación, según nuestras respectivas posiciones en la cultura maya, en la sociedad, y de acuerdo con nuestros compromisos institucionales. A mismo tiempo, las diversas problemáticas que surgen de una lectura más profunda de Säastal pueden contribuir a importantes debates acerca de nuestra cultura, identidad e idioma, $y$ también puede servir para los que quieren aprender más acerca de la cultura e idioma maya.

\section{BIBLIOGRAFIA}

Castillo Cocom, Juan A., y Quetzil E. Castañeda (eds.|.

2004 Estrutegias identitarias: educación y la ontrapobgia histárica en hicatón. Mérida, Yucatán: Universidad Nacional Pedagógica/Osea Cite/SEP.

Duarte Duarte, Ana Rosa

2000 "Las mujeres campesinas y el cambio cultural: el caso de dos organizaciones en la zona henequenera". Tesis de maestria. México: Escuela Nacional de Antropologia e Historia.

2006 "Espiritu de lucha: cuerpo, poder y cambio sociocultural". Tesis de doctorado. México: Universidad Autónoma Metropolitana.

2007 "Sujeto político y política investigativa", en DVD, XXVI Congreso del latin American Studies Association (LASA). Montreal: Latin American Studies Association.

, Byrt Wammack y Elsy Mena

1999 "Mujeres artesanas, género y proyectos productivos: retos y oportunidades". Informe final de investigación. México: Unidad de Ciencias Sociales del Centro Regional de Investigaciones Dr. Hideyo Noguchi/GIMTRAP-PEMSA.

Giddens, Anthony

2000 Un mundo desbocedo: los efectos de la globolizoción en nuestras vidos. Madrid: Taurus.

González Amadot, Roberto

2006 "Llegarón remesas por 24 mil mdd; reflejo del desempleo, afirma Ortiz", La jarnodo. México, 12 de mayo (sección Economia).

Grimonprez, Johan

1998 We Must Be over the Roinbow, catalogo de exhibición, Xunta de Galitia. Centro Gallego de Arte Contemporáneo (https/www.zapomatik.com). 
Lazos Chavero, Eena

1995 "Del maíz a la naranja en el sur de Yucatán: auge y dinámica de la huerta". l.a milpa en Micatón. Un sistema de producción agricala tradicianol, tomo 2 : 527-563, E. Hemández-X, E. Bello B. y S. Levy T. (comps.). México: Colegio de Postgraduados.

1999 "La milpa en el sur de Yucatán: ciclos y limitantes", Estedios de Cultura Maya, XX: 442-477, México: UNAM, Instituto de lnvestigaciones Filológicas, Centro de Estudios Mayas.

Máas Colli, Hilaria

2003 La reargentración de los gremies en Fuhi, Vocatán. Méxica: Lniversidad Autónoma de Yucatán.

Medina, Reneé, Lourdes Rejón, Beatriz Repetto y Margarita Rosales

2003 "Solares, rumbos y pueblos: organización social de los mayas peninsulares", La comunidad sin Mimites. Lo estructura social y contuntitaria de los puebles indigenes de México, vol. I: 291-399, S. Millän y J. Valle, (coords.). México: INAH.

Peniche Moreno, Claudia Paola

1999 "Resistencia indigena: la respuesta maya yucateca al proyecto reductor [1560-1697/". Tesis de licenciatura. Mérida, Yucatánz Universidad Autónoma de Yucatioln.

Rosales González, Margarita, y Amada Rubio Hertera

2004 "Entre la modernidad y la tradición manejo de recursos en común y empresas sociales en comunidades mayas del sur de Yucatán", ponencia presentada en The Commons in an Age of Clobal Transition. Ohallenges, Risks and Opportunities, Tenth Couference of the International Associotion for the Study of Common Pmperty. Oaxaca, Mexico, $30 \mathrm{pp}$. (httpy/dic.dlib.indiana.edu).

Torres Guevara, Luz Elba

2002 "Autoconsumo y reciprocidad entre los campesinos andinos: caso Fómeque*, Curodemas de Desarrollo Rural, 48: 79-98. Bogotá: Pontificia Universidad Javeriana.

Tuhiwai Smith, Linda

2002 Decolonizing Methodologies: Research and Indigenous Penpie. Nueva York: Zed Books:Lniversity of Otago Press.

Turner, Terence

2002 "Representations, Politics and Cultural Imagination in Indigenous Video", Media Warids, Faye D. Ginsburg, Lila Abu-Lughod y Brian Larkin (eds.). Berkeley: University of California Press. 
Savarino, Franco

1996 "Religión y sociedad en Yucatản durante el Porfiriato (1891-1911)", Historia de México, XLV1 (3): 617-651. México: Escuela Nacional de Antropología e Historia.

Schiwy, Freya

2002 "intelectuales subalternos? Notas sobre las dificultades de pensar en dialogo intercultural", interdisciplinar las ciencias socioles; geopoliticas del conocimbento y colonidad del poder. Perspections desde to andino. Catherine Walsh. Freya Schiwy y Santiago Castro Gómez (eds.). Quito: Universidad Andina Simón Bolivariabya-Yala.

Scott, James C

1985 Wapons of the Wak. Everyday Forms of the Peasant Resistance. New Haven: Yale University.

Sullivan, Paul

1989 Reconnaissonce Uhder Cover. Unfinished Conversations. Mayas and Fareigners Retween Two Wars. Nueva York: Alfred A. Knopf.

Wammack Weber, Byrt

1997 "Between Deleuze and Chaac: Bodies, Space and Power". Tesis de doctorado. Texas: University of Texas-Austin.

(dir.)

2004a Soistol: The Chiidren of the Sacred Groce, DDD. Chapel Hill, NC: UNC-Duke Consortium in Latin American \& Caribbean Studies.

$2004 \mathrm{~b}$ Sáastof: The Children of the Socred Grace. The Making of a film in Vocutec Maya. Chapel Hill, NC: UNC-Duke Consortium in Latin American \& Caribbean Studies. 